\title{
Toxicity and Antigenotoxic Effect of Hispolon Derivatives: Role of Structure in Modulating Cellular Redox State and Thioredoxin Reductase
}

Pogakula Chethna, ${ }^{\dagger, \perp}$ Shruti S. Iyer, ${ }^{\dagger, \perp}$ Vishwa V. Gandhi, ${ }^{\dagger, \S, \perp}$ Amit Kunwar, ${ }^{*}, \dagger, \S \odot$ Beena G. Singh, ${ }^{\dagger}$ Atanu Barik, ${ }^{* \dagger}$ Neduri V. Balaji," Modukuri V. Ramani," Gottumukkala V. Subbaraju," and K. Indira Priyadarsini

${ }^{\dagger}$ Radiation \& Photochemistry Division and ${ }^{\ddagger}$ Chemistry Division, Bhabha Atomic Research Centre, Mumbai 400085, India

${ }^{\S}$ Homi Bhabha National Institute, Anushaktinagar, Mumbai 400 094, India

${ }$ Natsol Laboratories Pvt. Ltd., Ramky Commercial Hub, J. N. Pharmacity, Visakhapatnam 531019, India

Supporting Information

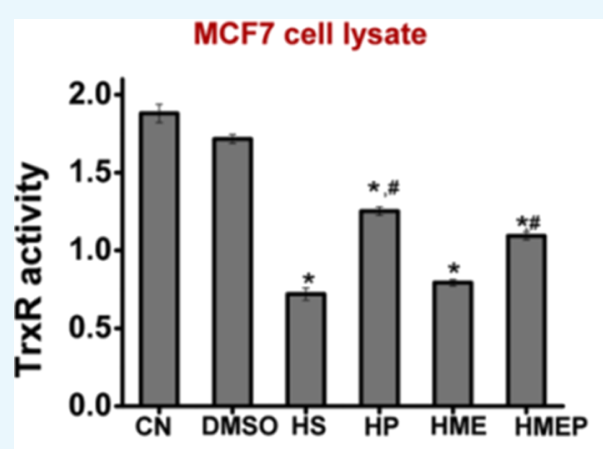

NADPH domain of TrxR involved in binding with HS

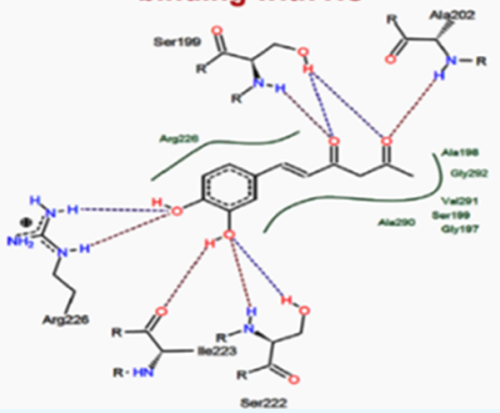

ABSTRACT: Hispolon (HS), a bioactive polyphenol, and its derivatives such as hispolon monomethyl ether (HME), hispolon pyrazole (HP), and hispolon monomethyl ether pyrazole (HMEP) were evaluated for comparative toxicity and antigenotoxic effects. The stability of HS derivatives in biological matrices followed the order HS $<\mathrm{HP} \approx \mathrm{HME}<\mathrm{HMEP}$. The cytotoxicity analysis of HS derivatives indicated that HP and HMEP were less toxic than HS and HME, respectively, in both normal and tumor cell types. The mechanisms of toxicity of HS and HME involved inhibition of thioredoxin reductase (TrxR) and/or induction of reductive stress. From the enzyme kinetic and docking studies, it was established that HS and HME interacted with the NADPH-binding domain of TrxR through electrostatic and hydrophobic bonds, resulting in inhibition of the catalytic activity. Subsequently, treatment with HS, HP, and HMEP at a nontoxic concentration of $10 \mu \mathrm{M}$ in Chinese Hamster Ovary ( $\mathrm{CHO})$ cells showed significant protection against radiation (4 Gy)-induced DNA damage as assessed by micronuclei and $\gamma$ $\mathrm{H} 2 \mathrm{AX}$ assays. In conclusion, the above results suggested the importance of phenolic and diketo groups in controlling the stability and toxicity of HS derivatives. The pyrazole derivatives, HP and HMEP, may gain significance in the development of functional foods.

\section{INTRODUCTION}

A recent focus of therapeutic research is to develop multifunctional compounds exhibiting pharmacological activities such as antitumor, anti-inflammatory, antioxidant, and antibacterial, among others. In this context, natural products derived from the biological sources have emerged as the first choice of researchers. Accordingly, several plant-/fungal-/ bacterial-derived natural products are in different stages of evaluation as new therapeutic agents. ${ }^{2-4}$ There has been also a growing interest among the researchers for exploring synthetic derivatives of natural products as a novel class of drugs with multiple activities and target specificity. ${ }^{5-7}$

Hispolon (HS) is one such bioactive polyphenol found in several medicinal mushrooms. It was isolated initially from
Inonotus Hispidus and hence named HS. ${ }^{8}$ Subsequently, HS was isolated from other species of mushrooms such as Phellinus Linteus and Phellinus Igniarius. ${ }^{9,10}$ There are increasing lines of evidence in the literature to suggest that HS exhibits a wide range of medicinal properties. For example, it has been reported for antiviral, ${ }^{11}$ hepatoprotective, ${ }^{12}$ immunomodulatory, ${ }^{13}$ and antiproliferative activities ${ }^{14-16}$ in different models. Of these, antitumor activity of HS has been studied in detail by different groups and it was observed that HS inhibits growth of cancer cells through induction of cell cycle arrest, apoptosis,

Received: March 6, 2018

Accepted: May 22, 2018

Published: June 1, 2018 
Scheme 1. Chemical Structures of HS and Its Derivatives

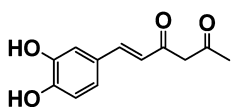

(E)-6-(3,4-dihydroxyphenyl)hex-5-ene-2,4-dione

Hispolon (HS)

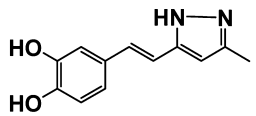

4-((E)-2-(3-methyl-1 H-pyrazol-5-yl)vinyl)benzene-1,2-diol

Hispolon pyrazole (HP)

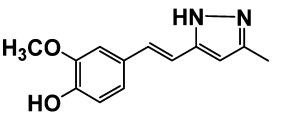

2-methoxy-4-((E)-2-(3-methyl-1H-pyrazol-5-yl)vinyl)phenol

Hispolon mono methyl ether pyrazole (HMEP)
(B)

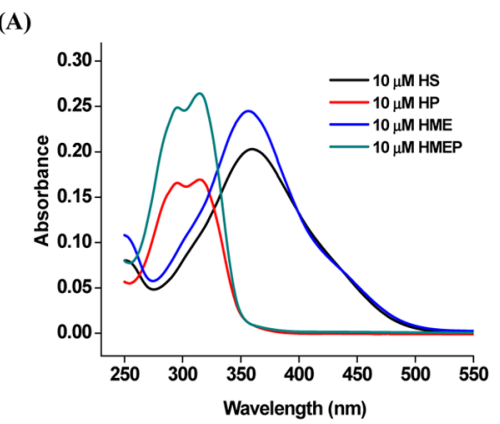

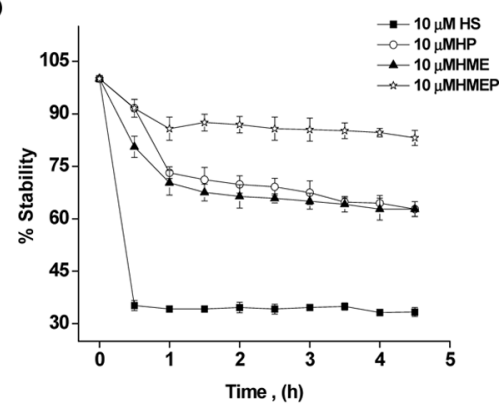

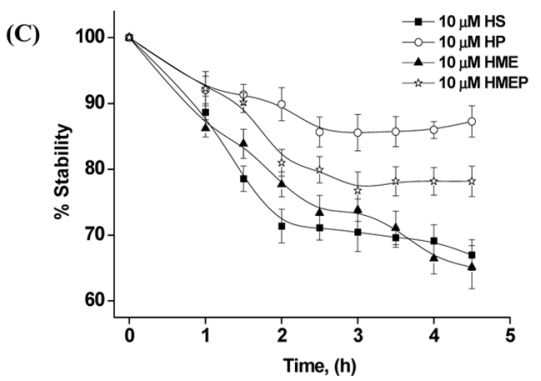

Figure 1. (A) Absorption spectra of HS derivatives (10 $\mu \mathrm{M})$ in PBS ( $\mathrm{pH} 7.4)$ containing 1\% DMSO. For the reference spectra, corresponding blanks without HS derivatives were used. (B,C) Degradation of HS derivatives $(10 \mu \mathrm{M})$ in physiological matrices such as PBS (pH 7.4) and cell culture medium containing $10 \%$ serum, respectively, following incubation at $37^{\circ} \mathrm{C}$ for a period of $4.5 \mathrm{~h}$. The final concentration of DMSO in the reaction mixture was $1 \%$. The absorbance was monitored at $360 \mathrm{~nm}$ for HS and HME and at $316 \mathrm{~nm}$ for HP and HMEP using a UV-visible spectrophotometer with an interval of $30 \mathrm{~min}$. The data are normalized to a value of $100 \%$ at zero time. Each value represents the mean of triplicate samples.

and suppression of metastasis. ${ }^{15,17-19}$ However, the underlying mechanisms responsible for these effects are not understood completely. Considering the importance of $\mathrm{HS}$ as a pharmacological agent, several of its new derivatives have been synthesized and evaluated for antiproliferative and antitubercular effects. $^{20,21}$ On similar lines, recently our group reported the abilities of $\mathrm{HS}$ and its derivatives such as hispolon pyrazole (HP), hispolon monomethyl ether (HME), and hispolon monomethyl ether pyrazole (HMEP) to scavenge reactive oxygen species (ROS) and to exhibit antioxidant activity in cell-free systems. ${ }^{22}$ The exposure of carcinogenic agents such as radiation, pollutants, and xenobiotics are known to increase the intracellular levels of ROS, leading to oxidative damages. $^{23,24}$ Although DNA is a stable, well-protected molecule, it is the most critical subcellular target of ROSinduced oxidative damages and is believed to be responsible for the onset of cell death, mutagenesis, and carcinogenesis. ${ }^{25}$ Therefore, any agent which can attenuate ROS (antioxidant activity) and the subsequent DNA damage (antigenotoxic activity) can help in reducing the initiation and progression of cancer. $^{26}$ This prompted us to hypothesize that HS and its derivatives may be explored for both chemotherapy and/or chemoprevention. However, the main hurdle in developing natural products as therapeutic agents is that they switch over from antioxidant to cytotoxic behavior depending on the dosage and type of the target cell. ${ }^{27,28}$ It is therefore necessary to identify the conditions under which such compounds show differential activities to take full advantage of their therapeutic potential. With this background, in the present study, HS and its three derivatives HME, HP, and HMEP were evaluated for the following: (i) chemical stability in biological matrices such as phosphate buffer and cell culture medium containing fetal bovine serum (FBS); (ii) cytotoxic effect in normal and tumor cells; (iii) mechanisms of antiproliferative effect in human breast cancer cell line (MCF7); and (iv) antigenotoxic effect against radiation exposure in Chinese Hamster Ovary (CHO) cell line. The purpose of this study is to provide scientific rationale for developing $\mathrm{HS}$ and its derivatives as chemo- 
(A)

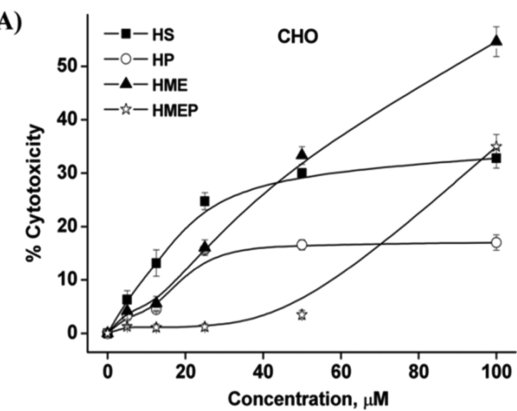

(C)

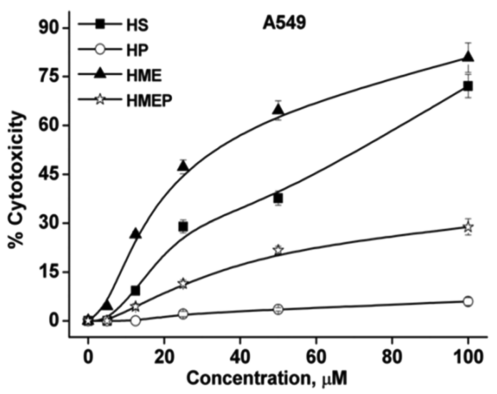

(B)

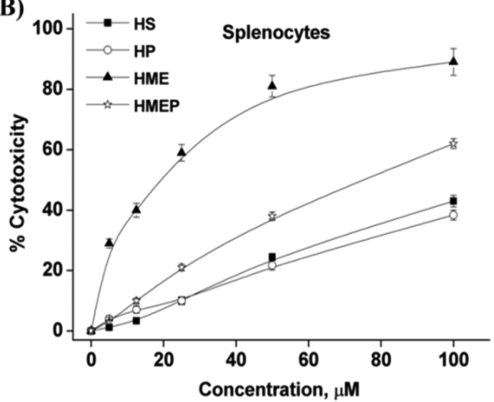

(D)

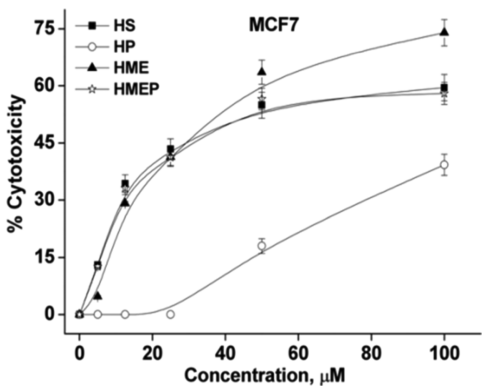

Figure 2. Cytotoxic effects of HS derivatives (5-100 $\mu \mathrm{M}$ ) in (A) CHO, (B) splenocytes, (C) A549, and (D) MCF7 cells by MTT assay after 48 h of their addition to cells. Data are represented as percentage toxicity with respect to control cells (DMSO, $0.1 \%)$. The results are presented as mean \pm standard error of the mean (SEM, $n=3$ ).

preventive and/or chemotherapeutic agents. The chemical structures of HS and its derivatives evaluated in the present study are shown in Scheme 1.

\section{RESULTS}

2.1. Assessment of Chemical Stability of HS and Its Derivatives. The chemical stabilities of HS, HP, HME, and HMEP were investigated by monitoring their degradation kinetics in physiological matrices such as phosphate buffer $(\mathrm{pH}$ 7.4 ) and cell culture medium containing $10 \%$ FBS. To address this, HS and its derivatives were first characterized for absorption spectrum. For this, stock solutions of HS and its derivatives were prepared in dimethyl sulfoxide (DMSO) and then added to phosphate buffer to achieve a final concentration of $10 \mu \mathrm{M}$ of each compound and the DMSO concentration of $1 \%$. The absorption spectra of all solutions were recorded in the wavelength range of $250-550 \mathrm{~nm}$. The spectra shown in Figure $1 \mathrm{~A}$ indicated that compounds HS, HP, HME, and HMEP exhibit absorption maximum at 360, 316, 360, and $316 \mathrm{~nm}$, respectively. There was an additional shoulder observed at 296 $\mathrm{nm}$ in the case of HP and HMEP. On the basis of this information, the degradation kinetics of each of the above compounds was followed by monitoring absorbance at their respective absorption maximum for a period of $4.5 \mathrm{~h}$ with an interval of $30 \mathrm{~min}$. The percent stability as a function of time calculated from the absorbance values normalized with respect to the absorbance at $0 \mathrm{~min}$ is shown in Figure $1 \mathrm{~B}, \mathrm{C}$ for phosphate buffer and cell culture medium, respectively. The degradation kinetics of HS, HP, HME, and HMEP initially decayed as a function of time and then reached saturation in both the matrices. Notably, all the four compounds were relatively more stable in cell culture medium (10\% FBS) compared to phosphate buffer (Figure 1B,C). For example HS, HP, HME, and HMEP degraded by $65,30,30$, and $15 \%$, respectively, within $1 \mathrm{~h}$ of their addition to phosphate buffer. In contrast, degradation of HS, HP, HME, and HMEP in culture medium (10\% FBS) was slower with about only $30,15,30$, and $20 \%$ degraded, respectively, in $2.5 \mathrm{~h}$ (Figure 1B,C). The methoxy derivative, HME, was more stable compared to HS, and the pyrazole derivatives, HP and HMEP, were more stable compared to the respective parent compounds HS and HME in both the matrices studied (Figure 1B,C). From the results, it is inferred that pyrazole substitution at the diketo position and methoxy substitution in the phenolic group enhance the stability of HS under physiological conditions.

2.2. Cytotoxicity Evaluation of HS and Its Derivatives. The toxicity of HS, HP, HME, and HMEP was evaluated in CHO, splenic lymphocytes, MCF7, and A549 cells. For this, cells were treated with increasing concentrations $(5-100 \mu \mathrm{M})$ of HS, HP, HME, and HMEP for $48 \mathrm{~h}$, and viability was determined using the MTT assay. The results as shown in Figure $2 \mathrm{~A}-\mathrm{D}$ indicated that $\mathrm{HS}$ induced a concentrationdependent toxicity in all the four cell types with relatively higher toxicity in tumor cells such as MCF7 and A549 at each of the concentrations tested (Figure 2). The $\mathrm{IC}_{50}$ (half maximal concentration to inhibit proliferation by $50 \%$ ) of HS was estimated to be $42,68,>100$, and $>100 \mu \mathrm{M}$, respectively, for MCF7, A549, CHO, and lymphocytes. The methoxy derivative, $\mathrm{HME}$, was found to be significantly higher toxic than HS in all the four cell types with an $\mathrm{IC}_{50}$ of $35,25,89$, and $20 \mu \mathrm{M}$, respectively, for MCF7, A549, CHO, and lymphocytes (Figure 2). Notably, pyrazole derivatives, HP and HMEP, showed significantly lesser toxicity compared to $\mathrm{HS}$ and HME, respectively, in all four cell types (Figure 2). The $\mathrm{IC}_{50}$ of $\mathrm{HP}$ in all the four cell types was $>100 \mu \mathrm{M}$, whereas HMEP exhibited an $\mathrm{IC}_{50}$ of $42 \mu \mathrm{M}$ in MCF7 cells, $75 \mu \mathrm{M}$ in lymphocytes and $>100 \mu \mathrm{M}$ in other two cell types. These results clearly suggested that pyrazole substitution at the diketo position reduced the toxicities of HS and HME. Furthermore, to understand the mode of cell death, MCF7 and A549 cells were treated with $\mathrm{HS}$ derivatives at $50 \mu \mathrm{M}$ (close to $\mathrm{IC}_{50}$ in these cell types) for $48 \mathrm{~h}$ and stained with propidium iodide 
(A)

MCF7
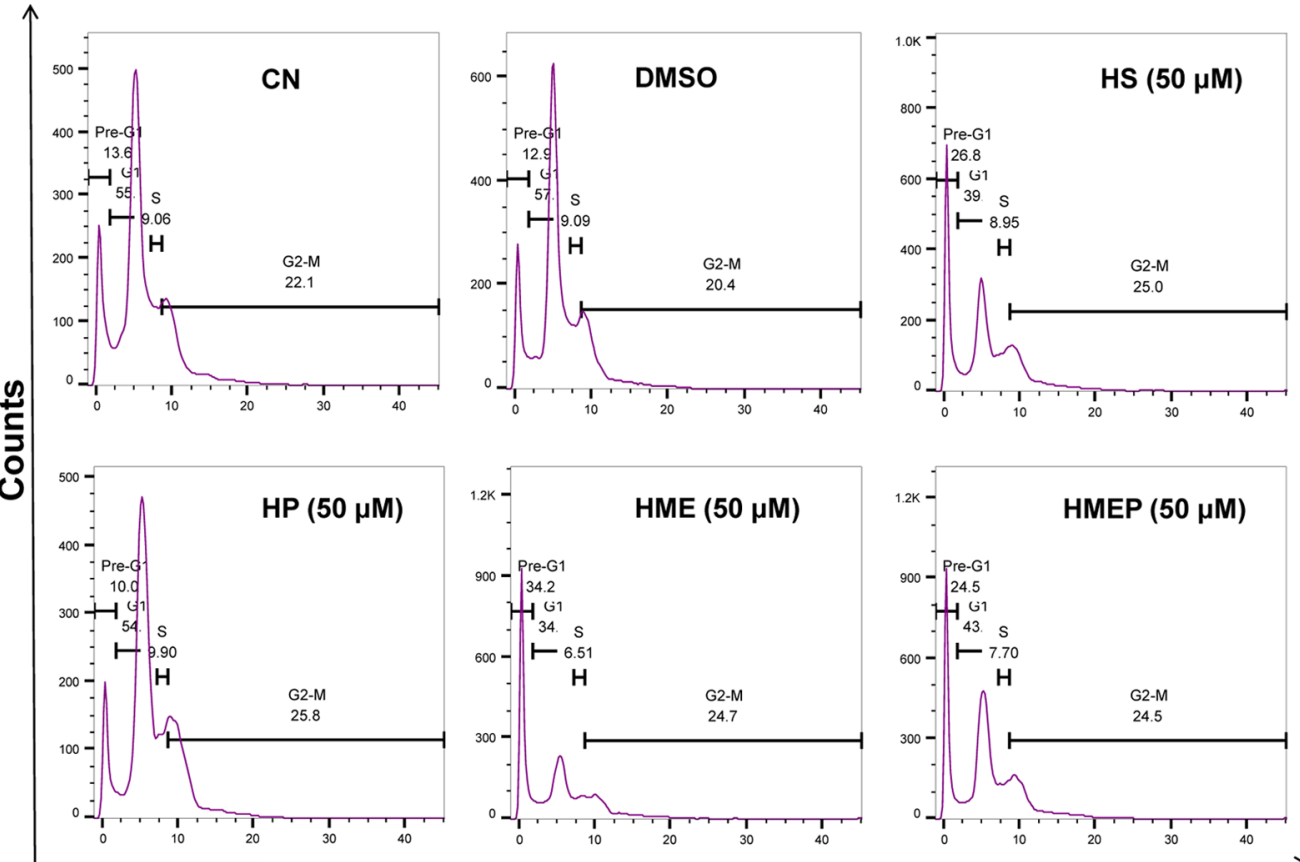

(B)
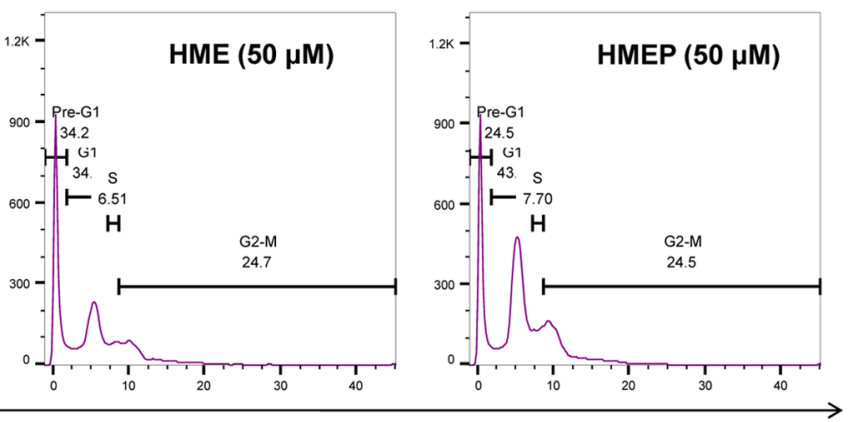

PI Intensity

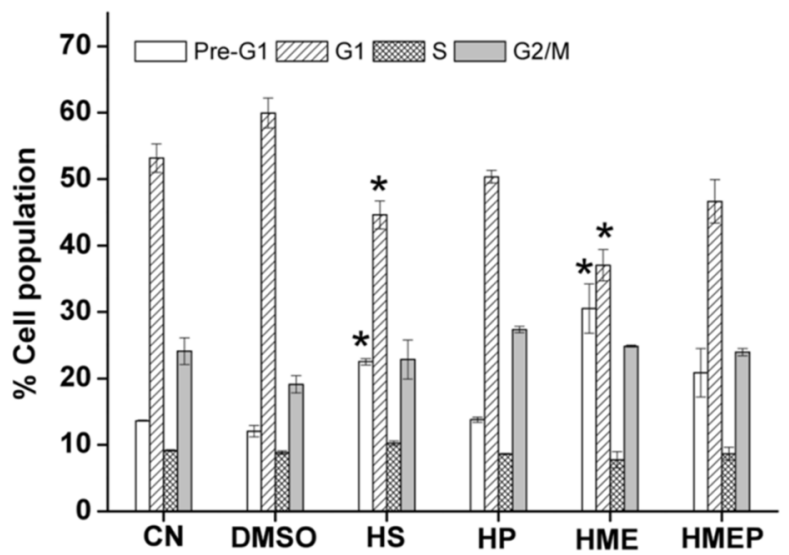

Figure 3. Effect of HS derivatives $(50 \mu \mathrm{M})$ on the cell cycle distribution in MCF7 cells as estimated by PI staining: (A) representative figure shows distribution of cells in different phase of cell cycle (G1, S, and G2/M) at $48 \mathrm{~h}$ after treatment with HS derivatives (B) bar graph shows the percentage (\%) of cells in different phases of cell cycle. The final concentration of DMSO in the cell culture was $0.1 \%$. Results are presented as mean \pm SEM $(n$ $=3) . * p<0.05$ as compared to DMSO control group. $\mathrm{CN}-$ control.

(PI) for cell cycle analysis through FACS. The distribution of cells into different phases of cell cycle is presented in Figures 3 and S1. It can be seen that treatment with HS and HME led to increase in the pre-G1 peak indicative of apoptosis in both MCF7 and A549 cells. Furthermore, pyrazole derivatives HP and HMEP were found to be significantly less effective than $\mathrm{HS}$ and HME, respectively, in inducing apoptosis (pre-G1) in above cell types, supporting MTT results (Figures 3 and S1 of the Supporting Information). Notably, HMEP treatment in A549 cells showed increase in the number of cells in the G2/M phase suggestive of cell cycle arrest (Figure S1 of the Supporting Information).

2.3. Effects of $\mathrm{HS}$ and Its Derivatives on the Intracellular Redox State in MCF7 Cells. The effect of HS, HP, HME, and HMEP on the cellular redox state was investigated in MCF7 cells at a treatment concentration of 25 $\mu \mathrm{M}$ for $48 \mathrm{~h}$. The ratio of glutathione (GSH) and oxidized glutathione (GSSG) is considered to be the indicator of the intracellular redox state. The effect of HS derivatives on the ratio of GSH and GSSG is presented in Figure 4A. The results indicated that treatment with HS did not cause any significant change in the basal GSH/GSSG in MCF7 cells. However, similar treatments with HP, HME, and HMEP led to $\sim 7$ folds increase in GSH/GSSG. The effect of HS derivatives on the activity levels of enzymes such as glutathione peroxidase (GPx), glutathione S-transferase (GST), and GR (known to be involved in regulation of GSH and GSSH) are presented in Figure $4 \mathrm{~B}-\mathrm{D}$, respectively. It can be seen that compounds HS and HME did not cause any significant change in the basal activity of GPx and GST; however, their corresponding pyrazole derivatives HP and HMEP showed inhibition of GPx activity by 31 and 40\%, respectively, and of GST by 31 and 

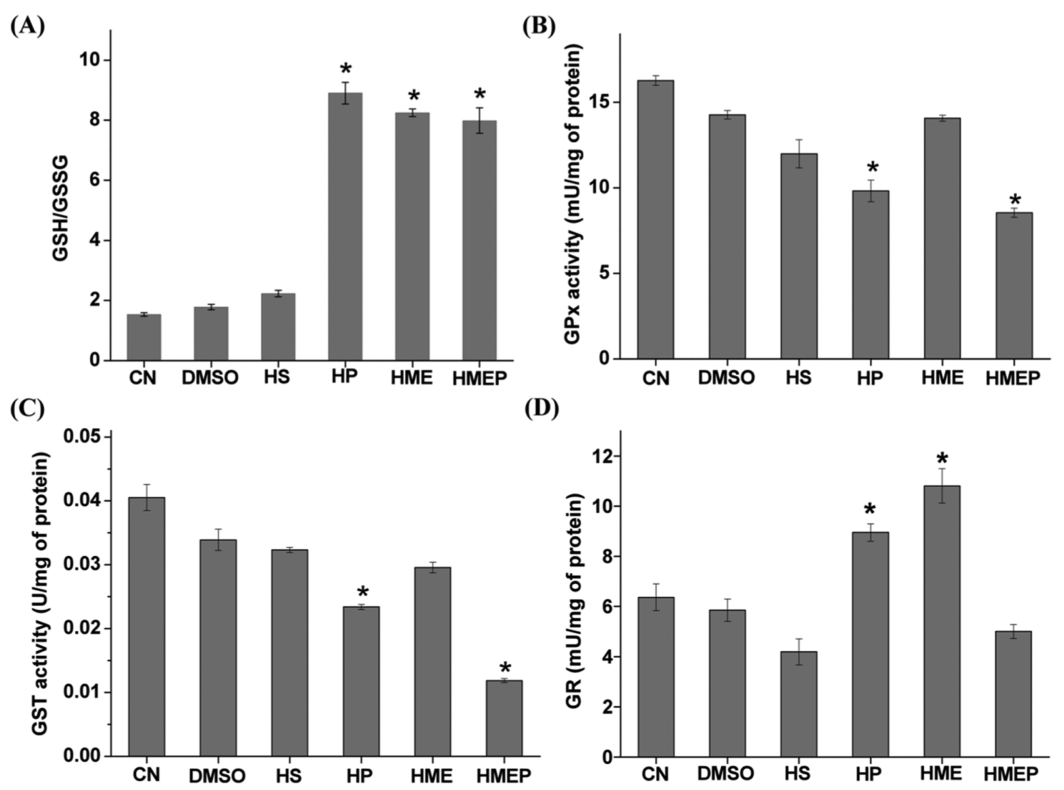

Figure 4. Effect of HS derivatives $(25 \mu \mathrm{M})$ on the intracellular redox state estimated at $48 \mathrm{~h}$ after their addition in to MCF7 cells. (A) Ratio of GSH and GSSG. (B) GPx activity level. (C) GST activity level. (D) GR activity level. The results are presented as mean \pm SEM $(n=3)$. * $p<0.05$ as compared to DMSO control group. $\mathrm{CN}-$ control.

(A)

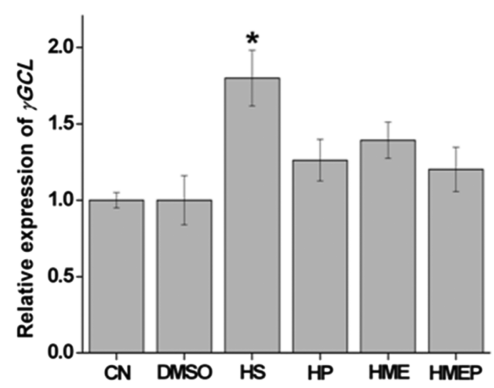

(B)

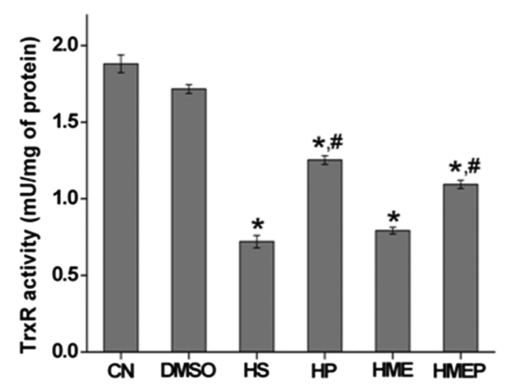

Figure 5. (A) Effect of HS derivatives $(25 \mu \mathrm{M})$ on the mRNA expression of $\gamma$-GCL monitored at $48 \mathrm{~h}$ after their addition in to MCF7 cells by RTPCR. Plot represents the expression of above gene normalized with respect to control group. Expression of $\beta$-actin mRNA was used as the internal control. (B) Effect of HS derivatives $(25 \mu \mathrm{M})$ on the TrxR activity level monitored at $48 \mathrm{~h}$ after their addition in to MCF7 cells. Results are presented as mean \pm SEM $(n=3) .{ }^{*} p<0.05$ compared to DMSO control group. ${ }^{*} p<0.05$ compared to HS or HME treated groups. CN-control.

$65 \%$, respectively. Furthermore, HS and HMEP did not affect the basal GR activity, whereas other two derivatives HP and HME significantly increased the GR level by 52 and $85 \%$, respectively. To address the effect of HS derivatives on the de Novo synthesis of GSH, the mRNA expression of $\gamma$-glutamylcysteine ligase $(\gamma$-GCL) (enzyme catalyzing GSH biosynthesis) was monitored by real-time polymerase chain reaction (RTPCR). The results shown in Figure 5A indicated that HS led to a marginal increase in mRNA expression of $\gamma$-GCL, whereas the other three derivatives did not affect its expression compared to control cells. Taken together, above results suggested that HP, HME, and HMEP induced reductive environment within cells through affecting the utilization-recycling pathway of $\mathrm{GSH}^{29}$

2.4. Effect of HS and Its Derivatives on Thioredoxin Reductase (TrxR) Activity in MCF7 Cells. Reduced form of thioredoxin (Trx) is known to play an important role in maintaining the cellular redox homeostasis. ${ }^{30}$ Therefore, HS and its derivatives were investigated for their effects on the activity level of TrxR in MCF7 cells, following treatment at 25 $\mu \mathrm{M}$ for $48 \mathrm{~h}$. The activity level of TrxR under different treatment conditions is presented in Figure 5B. It can be seen that all the four compounds HS, HP, HME, and HMEP led to significant inhibition of TrxR; however, pyrazole derivatives HP and HMEP were less inhibitory compared to parent compounds HS and HME, respectively (Figure 5B). The percent inhibition in TrxR activity by HS, HP, HME, and HMEP was observed to be $58,27,55$, and $37 \%$, respectively (Figure 5B).

2.5. Direct Inhibition of TrxR by HS and Its Derivatives in Cell-Free Systems. Furthermore, to understand whether TrxR is one of the direct targets of HS and its derivatives, HP, HME, and HMEP, were evaluated for TrxR inhibition in a cellfree system. In brief, purified TrxR was incubated with varying concentrations (5-100 $\mu \mathrm{M})$ of HS, HP, HME, and HMEP and then followed for enzyme kinetics using DTNB as the substrate and NADPH as the redox equivalent. The rate of formation of TNB by TrxR in the presence and absence of HS, HP, HME, and HMEP is presented in Figure 6. The percent TrxR activity calculated from above kinetics at two different concentrations (10 and $100 \mu \mathrm{M}$ ) of test compounds is shown in Figure S2 (of the Supporting Information). From these results, it is clear that compounds HS and HME did not cause much ( 15-25\%) 

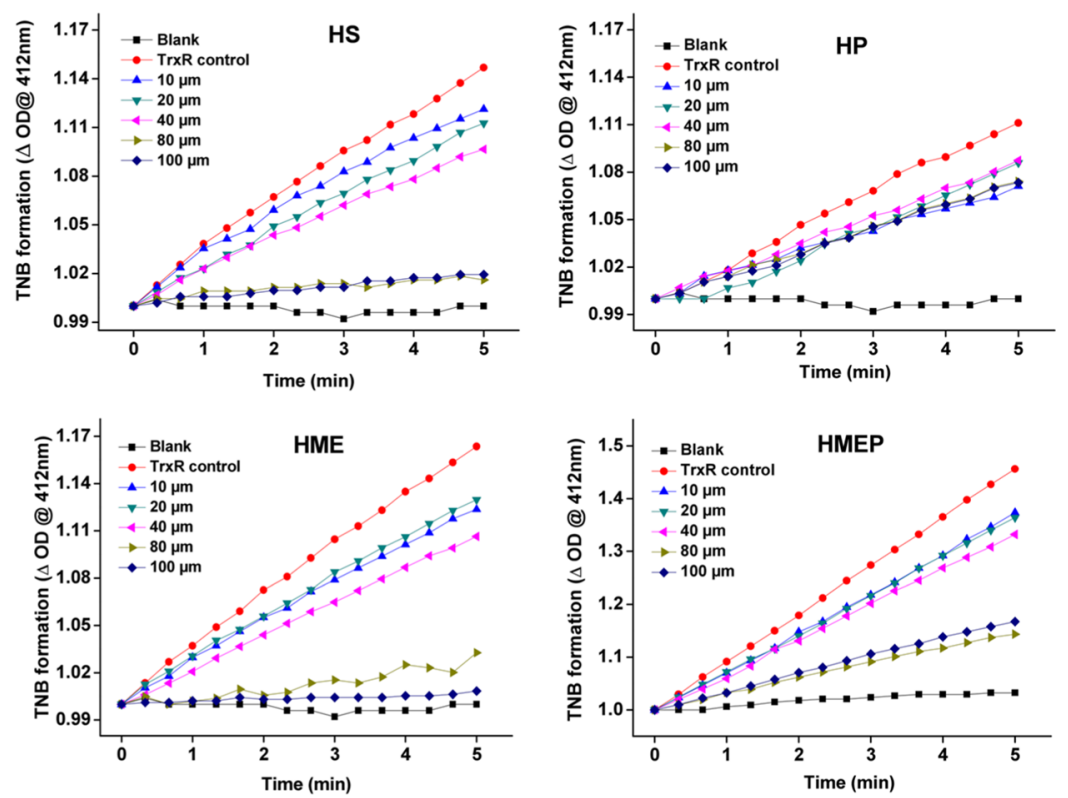

Figure 6. Reduction of DTNB in to TNB catalyzed by rat liver TrxR in the presence of the increasing concentrations of HS derivatives (5-100 $\mu \mathrm{M})$ in the cell-free system. The A412 was followed for 5 min against identical blank without TrxR.
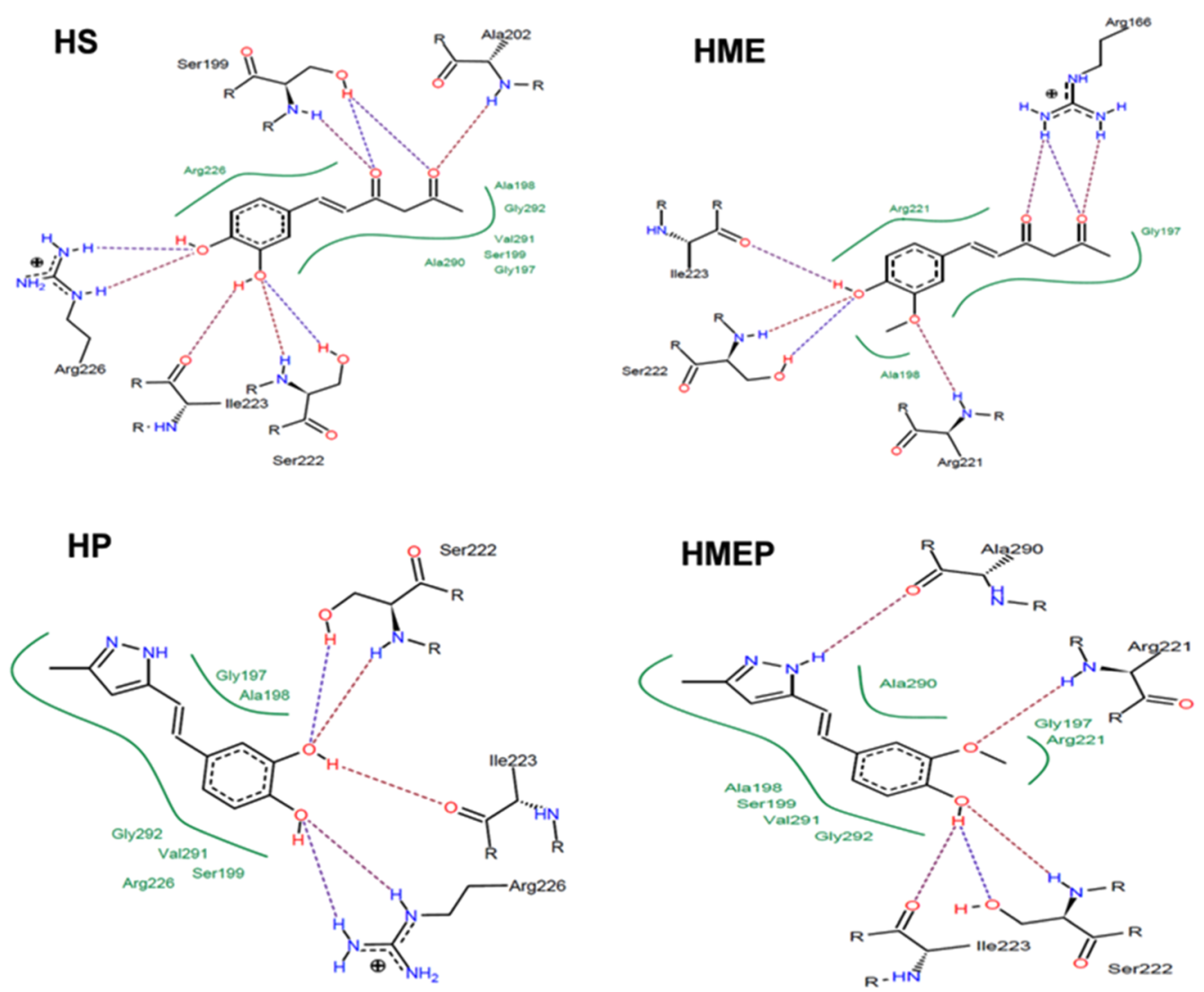

Figure 7. Schematic representation of the amino acids in the NADPH-binding domain of TrxR involved in binding with HS, HME, HP, and HMEP. Here, green line represents hydrophobic site of interaction, whereas the dotted line represents the electrostatic interaction.

inhibition of TrxR up to a concentration of $50 \mu \mathrm{M}$. However, as the concentration was increased to $100 \mu \mathrm{M}$, both the compounds led to almost complete $(\sim 85-95 \%)$ inhibition of TrxR. In comparison to HS and HME, the pyrazole derivatives, HP and HMEP, respectively, showed lesser inhibition of TrxR activity. Furthermore, to know whether inhibitions by HS derivatives are reversible in nature, a competition experiment was performed by varying NADPH concentration from 10-100 $\mu \mathrm{M}$, keeping the concentration of $\mathrm{HS}$ derivatives ( $\mathrm{HS}$ and HME, potent ones) fixed at $50 \mu \mathrm{M}$ and monitoring the rate of formation of TNB. The data were analyzed according to the Lineweaver-Burk plot as shown in Figure S3 (of the Supporting Information). The $K_{\mathrm{m}}$ (Michaelis-Menten constant) and $V_{\max }$ (maximum reaction velocity) values calculated 
(A)

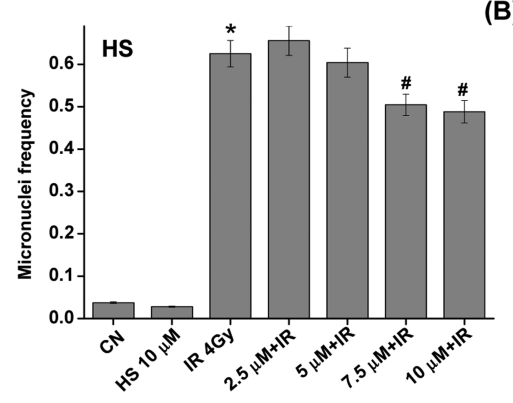

(C)

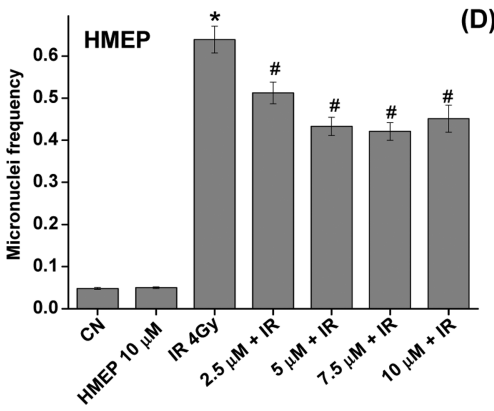

(B)

\section{)}
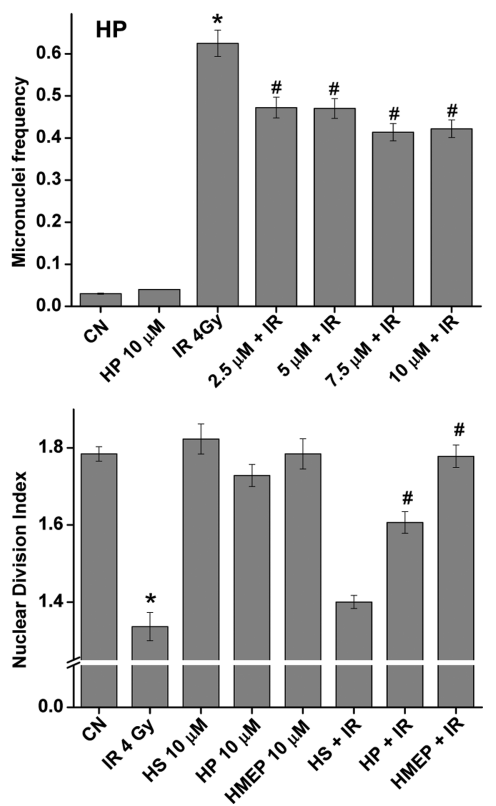

Figure 8. (A-C) Bar graphs show the effect of pretreatment with HS and its derivatives $(2.5-10 \mu \mathrm{M}$ for $2 \mathrm{~h})$ against radiation (4 Gy)-induced micronuclei formation in CHO cells. The results are presented as mean \pm SEM of 500 binucleate cells analyzed per treatment condition. (D) Effect of the pretreatment with HS and its derivatives $(10 \mu \mathrm{M}$ for $2 \mathrm{~h}$ ) on the NDI of irradiated (4 Gy) CHO cells. The results are presented as mean \pm SEM $(n=3) .{ }^{*} p<0.05$ compared to DMSO control group. ${ }^{\#} p<0.05$ compared to radiation control group. CN-control, IR-Radiation.

from the slope and intercept of above plots revealed that $K_{\mathrm{m}}$ of $\mathrm{NADPH}$ increased from $8.9 \mu \mathrm{M}$ in control reaction to 10.4 and $20 \mu \mathrm{M}$ in the presence of HS and HME, respectively. On the other hand, the $V_{\max }$ value of $1 \mathrm{nmole} / \mathrm{min}$ remained unaffected between the control reaction and those treated with HS and HME. Taken together, these results indicated of reversible inhibition of TrxR by HS ad HME. On the basis of these results, molecular docking studies were performed to identify possible binding sites of HS, HP, HME, and HMEP in the cytosolic TrxR. This protein has three important domains, namely interface domain harboring the active site, FAD-binding domain, and NADPH-binding domain, responsible for catalytic activity. All these three domains were considered for the computation of binding energy with all possible conformers (structure shown in Figure S4 of the Supporting Information) taking into account of both hydrophobic and electrostatic mode of interactions. From the calculated binding energy ( $\Delta G$ value), it was observed that HS and its derivatives interacted with both the interface domain and the NADPH-binding domain of TrxR. However, the trend observed from the experimental results (on inhibition of TrxR by HS derivatives in cellular and cell-free experiments) correlated with the $\Delta G$ values of interactions with the NADPH domain. The $\Delta G$ values of the interaction of different conformers of HS, HME, HP, and HMEP with the NADPH domain of TrxR are presented in Table S1 (of the Supporting Information). Among the different conformers, the keto form of HS and HME and the inner desmotropic form of HP and HMEP due to extended conjugation are expected to be the predominant forms in the hydrophobic protein environment. Considering $\Delta G$ values of these stable conformers, their binding to the NADPH domain of TrxR followed the order $\mathrm{HME}>\mathrm{HS} \approx \mathrm{HMEP}>\mathrm{HP}$. As per the favored pose of the ligand on the protein shown in Figure 7, HS and HP experience a similar amino acid environment during their binding to TrxR wherein amino acid residues, such as Ser 222, lle 223, and Arg 226 , are involved in electrostatic interaction with the phenolic hydroxyl group, whereas Gly 292, Ser 199, Ala 198, and Val 291 are involved in hydrophobic interaction with aromatic and the $\alpha, \beta$-unsaturated moieties. Notably, methylated derivatives of HS and HP differed in their amino acid environment involved in the binding. For example, amino acid residues Ala 290, Ala 198, Val 291, Gly 292, and Ser 199 in case of HMEP and Arg 221, Gly 197, and Ala 198 in case of HME were responsible for hydrophobic interaction. On the other hand, the phenolic hydroxyl group in HME and HMEP was bound to IIe 223 and Ser 222 via electrostatic interaction. Additionally, electrostatic interactions were contributed by Ala 290 and Arg 221 for HMEP and by Arg 166 and Arg 221 for HME. Taken together, these results suggested that the inhibitory effect of HS and HME on TrxR is due to their interaction with its NADPHbinding domain.

2.6. Effect of HS and Its Derivatives on the RadiationInduced Micronuclei Formation in CHO Cells. Because HS, HP, and HMEP showed negligible toxicity $(<10 \%)$ in cells up to a concentration of $10 \mu \mathrm{M}$, these compounds were considered suitable for evaluating the antigenotoxic effect against radiation exposure. For this, $\mathrm{CHO}$ cells, being an ideal model cellular system for genotoxicity evaluation, ${ }^{31,32}$ were pretreated with test compounds $(2.5-10 \mu \mathrm{M})$ for $2 \mathrm{~h}$ and irradiated at $4 \mathrm{~Gy}$. The micronuclei frequency was determined at $18 \mathrm{~h}$ postirradiation, and the results are presented in Figure $8 \mathrm{~A}-\mathrm{C}$. It was observed that exposure to radiation led to a significant increase in micronuclei frequency. Pretreatment with HS did not affect the radiation-induced micronuclei formation up to a concentration of $5 \mu \mathrm{M}$; however, at higher concentrations of 7.5 and $10 \mu \mathrm{M}$, it showed reduction in micronuclei formation by 20 and $22 \%$, respectively (Figure $8 \mathrm{~A}$ ). In contrast, pyrazole derivatives $\mathrm{HP}$ and HMEP showed reduction in radiation-induced micronuclei formation by $\sim 25 \%$ at concentration as low as $2.5 \mu \mathrm{M}$ (Figure $8 \mathrm{~B}, \mathrm{C}$ ). Increasing the concentration up to $10 \mu \mathrm{M}$ did not show much change in the protective effect of HP and HMEP (Figure 8B,C). The 
(A)

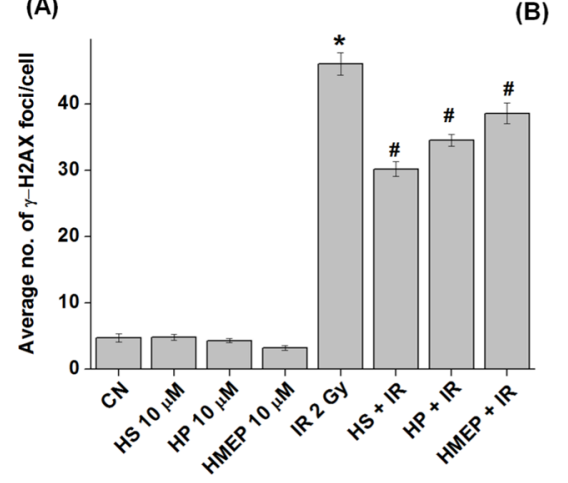

(B)

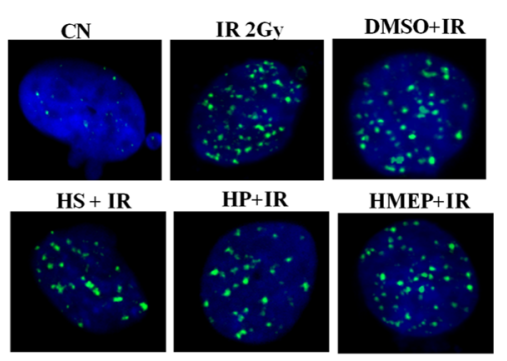

Figure 9. (A) Bar graphs show the average number of gamma $\gamma \mathrm{H} 2 \mathrm{AX}$ foci per nucleus under different treatment conditions in $\mathrm{CHO}$ cells. The cells were treated with HS and its derivatives at a concentration of $10 \mu \mathrm{M}$ and were exposed to $2 \mathrm{~Gy}$ of $\gamma$-radiation. (B) Representative fluorescent images show $\gamma \mathrm{H} 2 \mathrm{AX}$ foci in nucleus from each treatment group. Magnification-63X. The results are presented as mean \pm SEM of 50 cells analyzed per treatment condition. $\mathrm{CN}-$ control, IR-radiation.
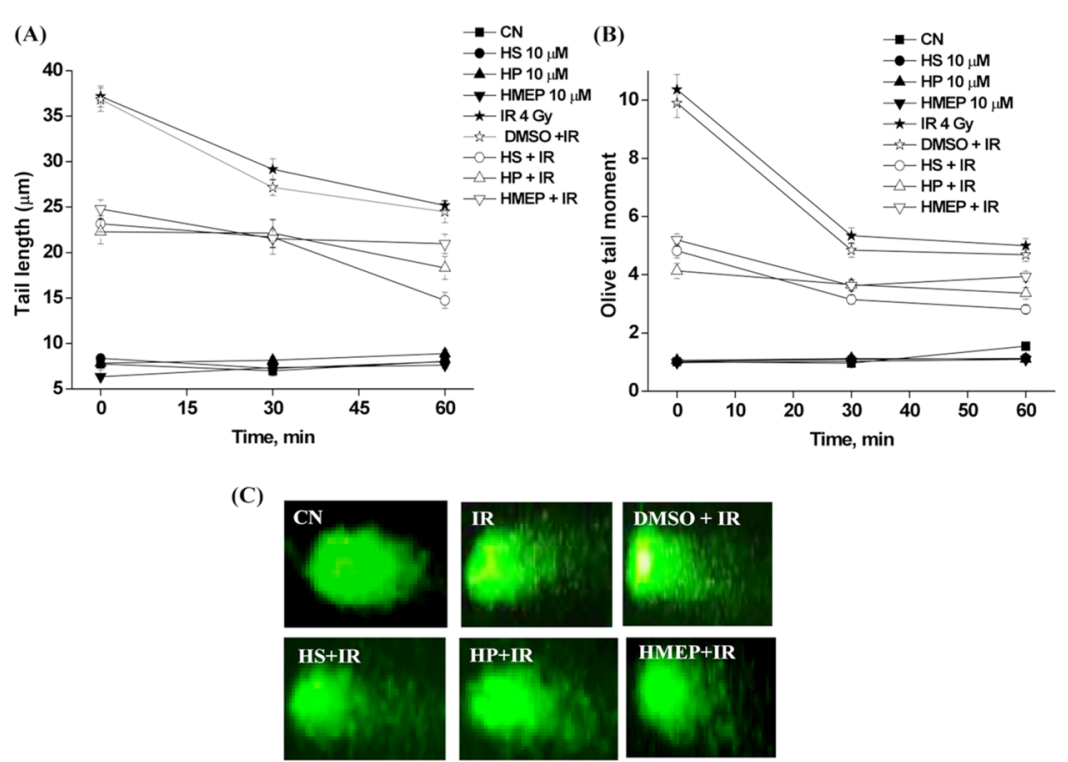

Figure 10. (A) Effect of the pretreatment with HS and its derivatives $(10 \mu \mathrm{M})$ on the radiation (4 Gy)-induced DNA damage as estimated by single cell gel electrophoresis in $\mathrm{CHO}$ cells. (B) Representative fluorescent images show comet in different treatment groups at 30 min postirradiation. Results are presented as mean $\pm \mathrm{SEM}, n=3$. CN-control, IR-radiation. ${ }^{*} p<0.05$ as compared to respective control groups. ${ }^{\#} p<0.05$ compared to radiation control groups.

compound control groups did not show any induction of micronucleus, suggesting them to be safe at tested concentrations. Because all the three compounds showed the saturation effect with respect to protection from micronuclei formation at a concentration of $10 \mu \mathrm{M}$, all our subsequent studies were carried out only at this concentration. Nuclear division index (NDI) is a marker of cell proliferation. To determine this parameter, $\mathrm{CHO}$ cells pretreated with $\mathrm{HS}, \mathrm{HP}$, and HMEP $(10 \mu \mathrm{M}$ for $2 \mathrm{~h})$ were exposed to $\gamma$-radiation at 4 Gy. As shown in Figure 8D, irradiation decreased the NDI and pretreatment with HS did not affect this much. In contrast, HP and HMEP showed increase in NDI as compared to radiation control (Figure 8D). The compound control groups showed NDI comparable to sham control (Figure 8D). The representative images showing mononucleated, binucleated, and trinucleated cells are presented Figure S5 (of the Supporting Information).

2.7. Effect of HS and Its Derivatives on the RadiationInduced Early DNA Damage in CHO Cells by $\gamma-\mathrm{H} 2 \mathrm{AX}$ Assay. The effect of HS derivatives on radiation-induced acute
DNA damage was studied at $30 \mathrm{~min}$ postirradiation. For this, $\mathrm{CHO}$ cells, pretreated (10 $\mu \mathrm{M}$ for $2 \mathrm{~h}$ ) with $\mathrm{HS}, \mathrm{HP}$, and $\mathrm{HMEP}$, and irradiated at $2 \mathrm{~Gy}$, were examined for $\gamma-\mathrm{H} 2 \mathrm{AX}$ foci per cell. The result of this assay is presented in Figure 9. It can be seen that irradiation led to a significant increase in the number of $\gamma$-H2AX foci by almost 10 folds. Pretreatment with all the three compounds showed decrease in the number of $\gamma$ $\mathrm{H} 2 \mathrm{AX}$ foci compared to radiation control, suggesting protection from radiation induced acute DNA damage (Figure 9). The compounds HS and HP were marginally better than HMEP in this assay. The compound control groups did not show any induction of $\gamma$-H2AX foci (Figure 9).

2.8. Effect of HS and Its Derivatives on the RadiationInduced DNA Repair. The effect of HS derivatives on DNA repair kinetics was studied by comet assay. For this, $\mathrm{CHO}$ cells, pretreated (10 $\mu \mathrm{M}$ for $2 \mathrm{~h}$ ) with HS, HP, and HMEP, were irradiated at $4 \mathrm{~Gy}$ and evaluated for DNA damage parameters like tail length (TL) and olive tail moment (OTM) as a function of time starting from 0 to $60 \mathrm{~min}$. The results of these parameters and the representative images of SYBR Green-II 
stained nuclei from different groups are presented in Figure 10. The exposure to radiation led to a significant increase in DNA damage parameters, which reduced with the progress of time suggesting the normal repair process (Figure 10). Pretreatment with HS, HP, and HMP showed a significant decrease in DNA damage parameters compared to the radiation control group at each of the time point studied. Notably HS and its derivatives reduced DNA damage parameters at $0 \mathrm{~min}$ itself compared to radiation control (Figure 10). This suggested that HS and its derivatives prevented the radiation-induced initial DNA damage instead of augmenting the DNA repair efficiency. The compounds HS and HP were more effective than HMEP in reducing the radiation-induced initial DNA damage (Figure 10).

2.9. Effect of HS and Its Derivatives on the Radiation Induced ROS Generation in CHO Cells. The effect of pretreatment ( $10 \mu \mathrm{M}$ for $2 \mathrm{~h}$ ) with HS, HP, and HMEP on the intracellular ROS level was monitored at 30 min postirradiation. The results shown in Figure 11 indicated that exposure to

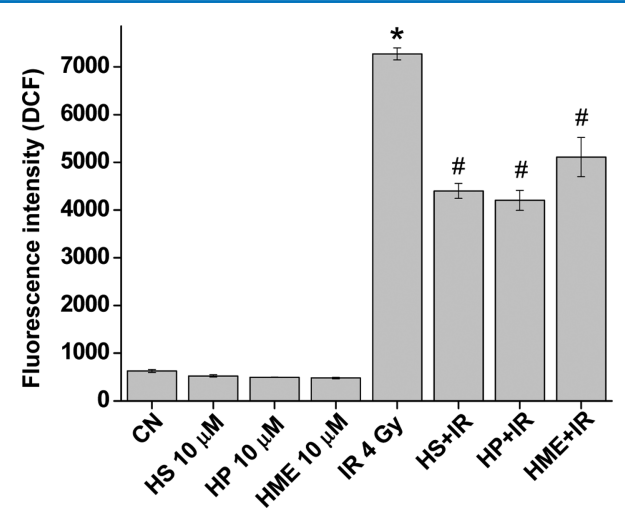

Figure 11. Effect of $\mathrm{HS}$ and its derivatives on radiation induced ROS levels in CHO cells: intracellular ROS level was estimated at $30 \mathrm{~min}$ after irradiation using the DCF-DA probe $\left(\lambda_{\text {ex }}-488 \mathrm{~nm}\right)$. The fluorescence intensities of oxidized DCF under different treatments are representative of the ROS levels. $* p<0.05$ when compared to control; ${ }^{\#} p<0.05$ when compared to radiation control.

radiation (2 Gy) led to a significant increase in the ROS generation compared to the sham control. Pretreatment with HS, HP, and HMEP resulted in significant reduction in the ROS level by 40,43 , and $30 \%$, respectively, as compared to radiation control (Figure 11). The compound control groups did not show any significant change in basal ROS level (Figure 11).

\section{DISCUSSION}

HS, a natural product obtained from mushroom, has attracted a lot of interest among researchers for its multiple pharmacological activities such as antioxidant, anticancer, anti-inflammatory, and antibacterial, among others. ${ }^{8,11-16}$ This has led researchers to synthesize new derivatives of HS and to explore them for various pharmacological activities. ${ }^{20-22}$ In the present study, four compounds namely HS, HME, HP, and HMEP have been evaluated for chemical stability, toxicities, and antigenotoxic effects to identify a potential lead phytochemical for cancer chemotherapy and chemoprevention.

The stability of $\mathrm{HS}$ and its derivatives was studied under physiological conditions $\left(37^{\circ} \mathrm{C}, \mathrm{pH}=7.4\right)$ in two different biological matrices such as phosphate buffer and complete culture medium. ${ }^{33}$ Results clearly indicated that HS is least stable irrespective of the biological medium. In contrast, HME having the hydroxyl group replaced with the methoxy group in the ring structure showed higher stability. Previously, in the case of curcumin, a structural analog of HS, it has been shown that the phenolic hydroxyl group can undergo auto-oxidation, and accordingly, the increased stability of HME over HS can be attributed to the presence of the methoxy group in the ring structure. ${ }^{34}$ Furthermore, the conjugated diene structure of curcumin also contributes to instability through hydrolysis under neutral-basic conditions. ${ }^{35}$ With a similar analogy, blocking the diketo group with the pyrazole group further increased the stability of HS and HME in biological matrices. In general, the presence of serum (10\%) increased the chemical stability of HS and its three derivatives, which is in line with stability reports of curcumin. ${ }^{33}$ Having understood this, HS and its derivatives were screened for toxicity in normal cells such as $\mathrm{CHO}$ and lymphocytes and in tumor cells such as A549 and MCF7. The results indicated that HS induced selective toxicity in tumor cells, whereas its methoxy derivative (HME) was toxic in both normal and tumor cell types. Interestingly, the compounds, HP and HMEP, wherein the diketo moiety is replaced with the pyrazole group showed lesser toxicity compared to respective parent compounds, HS and HME, in all the four cell types investigated. The cell cycle analysis in the tumor cells such as MCF7 and A549 revealed that HS and HME caused the pre-G1 peak indicative of apoptosis, whereas HMEP treatment showed cell cycle arrest (G2/M). Furthermore, to understand the mechanisms responsible for the differential toxicity of HS derivatives, their effects on cellular redox state were studied in the most sensitive cell type, MCF7. Redox state is considered to be the most critical parameter controlling the fate of cells. ${ }^{29,36}$ The results indicated that HS did not affect the ratio of GSH and GSSG, whereas the other three derivatives HME, HP, and HMEP significantly increased this ratio, suggestive of reducing environment within cells. Intracellular level of GSH is mainly regulated by its de Novo synthesis, recycling, and utilization. ${ }^{29}$ For example; endogenous synthesis of GSH is catalyzed by $\gamma$-GCL. Similarly, enzymes such as GPx and GST are involved in the utilization of GSH, whereas GR recycles GSSG into GSH. The results on the measurement of these enzymes indicated that treatments with HME, HP, and HMEP caused a significant increase in the level of GR with concurrent decrease in the levels of GPx and GST. Notably HME, HP, and HMEP did not show any significant change in the mRNA expression of $\gamma$-GCL. Taken together, above results indicated that HP, HME, and HMEP induced reductive environment within cells by affecting the utilizationrecycling pathway of GSH and not by inducing GSH biosynthesis.

There are growing lines of evidence in the literature that alterations in the ratio of GSH and GSSG toward a more reduced status lead to cell cycle arrest and in turn cell death. ${ }^{37,38}$ However, toxicity results of HS derivatives were not in agreement with the above assumption, suggesting the involvement of factors in addition to just the redox state. Recently, Trotter and Grant reported that the reduced form of Trx plays an important role in rescuing the cells from reductive stress. ${ }^{30}$ Additionally, Trx is required for DNA synthesis and subsequent progression of cell cycle. ${ }^{39}$ The reduced form of Trx is maintained by TrxR, and so, the inhibition or decrease in the activity of this enzyme is known to cause antiproliferative effects and/or cytotoxicity. ${ }^{40,41}$ This prompted us to presume that HS derivatives might be targeting TrxR to express their 
toxicity in cells. To address this, the effect of HS, HP, HME, and HMEP on the activity of TrxR was investigated. Notably, results from these studies indicated that both HS and HME led to significantly higher inhibition of TrxR activity compared to their pyrazole derivatives. From the docking studies, it was established that HS and HME interacted with the NADPHbinding domain of TrxR by involving electrostatic and hydrophobic bonds and thus justifying their inhibitory effect on enzyme activity. The competition kinetics indicated that the inhibitory effect of HS and HME on TrxR was reversible. However, future studies are needed to validate these results through mass spectroscopy to completely rule out the possibility of covalent modification of TrxR through HS and HME at higher concentrations of treatments. Additionally in the present study, docking analysis has been restricted to probe the interactions of HS derivatives only in the catalytic domains of TrxR, and therefore, it is of our interest in future to explore additional interactions beyond catalytic domains using other docking programme such as DogSite scorer. It is also worth mentioning that curcumin and other plant-derived phenolic compounds have been reported to inhibit TrxR, however through interactions with the interface domain. ${ }^{42}$ Taken together, these observations explained that even though HP and HMEP induced reductive environment in the cells, they exhibited lesser toxicity because of maintenance of TrxR. Similarly, the selective toxicity of HS could be attributed to the inhibition of TrxR, which is known to be overexpressed in tumor cells. ${ }^{43}$ On contrary, the inhibition of TrxR coupled with reductive stress accounted for the significantly higher toxicity of HME over other HS derivatives in all the cell types investigated. To the best of our knowledge, this is the first study reporting the involvement of reductive stress and inhibition of TrxR as mechanisms responsible for the antiproliferative effects of $\mathrm{HS}$ and its derivative such as HME in tumor cells.

Recently, HS, HME, HP, and HMEP were reported for their abilities to scavenge ROS and to exhibit antioxidant activity in cell-free systems. ${ }^{22}$ Additionally, observations of the present study that HP and HMEP maintain reductive environment within cells prompted us to hypothesize that such compounds can also be explored to protect cells from ROS-induced DNA damage, which is a prerequisite for developing any chemopreventive agent. ${ }^{26,28}$ To address this issue, we employed $\mathrm{CHO}$ cells of epithelial origin. These cells have been widely used in genotoxicity-related research work. ${ }^{44}$ Irradiation is known to induce DNA damage in cells through radiolytically generated ROS. $^{45}$ If the presence of HS compounds can prevent this process, they are expected to reduce the predisposition of genetic instability and in turn the oncogenic transformation of the cells by genotoxic agents. Of the three HS derivatives, HME was not considered for this study as this compound was toxic to normal cells even at low concentrations $(<10 \mu \mathrm{M})$. HS and the other two derivatives, HP and HMEP, showed almost similar efficacy in preventing the radiation-induced DNA damage as monitored by $\gamma-\mathrm{H} 2 \mathrm{AX}$ and micronuclei assays. Furthermore, it was observed that pretreatment with HS, HP, and HMEP did not influence the repair kinetics but prevented the radiationinduced initial DNA damage. In line with these results, pretreatment with HS, HP, and HMEP showed decrease in the ROS level following radiation exposure. Thus, the antigenotoxic effect of HS derivatives is attributed to the scavenging of radiation-induced ROS generation.

In conclusion, HS exhibited both cytotoxic and antigenotoxic effects depending on concentration and cell type. The chemical instability of HS under physiological conditions may be a cause of concern in its pharmacological application. Substitution of the hydroxyl group with the methoxy group in the ring structure of HME improved its stability, however increased the toxicity irrespective of cell type, making it unsuitable for pharmacological application. The mechanisms of toxicity of HS and HME involved inhibition of TrxR and concurrent induction of reductive stress. The pyrazole derivatives HP and HMEP showed not only improved stability but also potent antigenotoxic effect against radiation exposure. Thus, HP and HMEP as derivatives of a natural product (HS) may gain significance as dietary supplements for chemoprevention.

\section{MATERIALS AND METHODS}

4.1. Chemicals and Reagents. HS, HME, HP, and HMEP were synthesized, purified, and characterized as reported previously. ${ }^{21}$ DMSO, GSH, $\beta$-nicotinamide adenine dinucleotide 2 -phosphate reduced tetra sodium salt hydrate (NADPH), $\mathrm{GSH}$ reductase, cumene hydroperoxide, cytochalasin B, diethyl pyrocarbonate, acridine orange, CelLytic- reagent, paraformaldehyde, $o$-phthalaldehyde, $N$-ethylmaleimide, meta-phosphoric acid, TRI reagent, high and low melting point agarose, dipotassium hydrogen phosphate, potassium dihydrogen phosphate, sodium chloride, potassium chloride, SYBR Green-II dye, protease inhibitor cocktail, and amplification grade DNase from Sigma Chemical Company (St. Louis, MO, USA) were purchased from local agents. The cDNA synthesis kit and ProLong Gold antifade mountant with DAPI from Thermo Scientific (USA), 2X SYBR green PCR mix from Roche Chemical Co (Indianapolis, USA), and $2^{\prime}, 7^{\prime}$-dichlorofluorescin diacetate (DCFDA) from Molecular Probes (USA) were procured through local agents. Dulbecco's Modified Eagle Medium (DMEM), FBS, trypsin-EDTA, penicillin, and streptomycin were purchased from HiMedia, India. Anti phospho-histone H2AX (ser-139) human monoclonal IgG were purchased from Upstate, USA. Alexa Fluor 488 rabbit antihuman IgG and PI from Invitrogen (USA) were purchased through local agents. Bradford protein assay kit was purchased from Bangalore Genei, India. The gene specific primers for RTPCR were custom-synthesized from local agents. All other chemicals with maximum available purity were purchased from reputed local manufacturers/suppliers.

4.2. Cell Culture and Compound Treatment. Human lung carcinoma (A549), MCF7, and CHO cells were maintained in DMEM medium supplemented with 10\% FBS, $100 \mathrm{U} / \mathrm{mL}$ penicillin, and $100 \mu \mathrm{g} / \mathrm{mL}$ streptomycin. Splenic lymphocytes were freshly isolated from $\mathrm{BALB} / \mathrm{c}$ mice under aseptic conditions according to the method described earlier ${ }^{46}$ and maintained in RPMI-1640 medium supplemented with FBS and antibiotics as described above. All the cell types were grown in a humidified incubator (MCO-230AICUVH, Panasonic) with $5 \% \mathrm{CO}_{2}$ and atmospheric $\mathrm{O}_{2}(20 \%)$ at 37 ${ }^{\circ} \mathrm{C}$. The stock solution of $\mathrm{HS}$ and its derivatives was prepared in DMSO and diluted with complete culture medium or phosphate-buffered saline (PBS) to achieve desired concentrations. The concentration of DMSO in cellular studies was kept constant within permissible limits of toxicity (0.1\%).

4.3. MTT Assay. Cells $\left(\sim 2 \times 10^{3}\right)$ suspended in $200 \mu \mathrm{L}$ of complete culture medium were seeded in each well of 96-well plates. The cells were allowed to attach and grow for $12 \mathrm{~h}$, treated with desired concentrations of HS and its derivatives for $48 \mathrm{~h}$, and then processed for MTT as described previously. ${ }^{47}$ The percentage (\%) cytotoxicity was calculated from the 
decrease in absorbance at $570 \mathrm{~nm}$ of treated groups as compared to that of the control group.

4.4. Biochemical Assays. Intracellular levels of reduced GSH, GSSG, GPx, GST, and TrxR were determined at $48 \mathrm{~h}$ after treatment with $\mathrm{HS}$ and its derivatives. In brief, cell lysate was prepared using CelLytic $\mathrm{M}$ containing protease inhibitor cocktail and around $\sim 100 \mu \mathrm{g}$ of protein was used for the estimation of TrxR activity using a commercially available kit as per the manufacturer's instructions and of other enzymes, according to methods reported previously. ${ }^{46,48}$ Protein content in the cell lysate was determined using Bradford assay as per manufacturer's instruction.

4.5. TrxR Inhibition Assay. The ability of HS or its derivatives to act as the inhibitor of mammalian TrxR was evaluated by setting up a reaction volume of $200 \mu \mathrm{L}$ containing assay buffer (50 mM Tris-HCl, $1 \mathrm{mM}$ EDTA, $\mathrm{pH} 7.4$ ), 100 $\mu \mathrm{M} \mathrm{NADPH}$, rat liver $\operatorname{TrxR}(50 \mathrm{nM})$, and the increasing concentrations of HS or its derivatives. ${ }^{49}$ The reaction mixture was incubated at $37{ }^{\circ} \mathrm{C}$ for $30 \mathrm{~min}$, and following this, DTNB $(6 \mathrm{mM})$ was added to initiate the reaction. The activities were determined by monitoring the formation of TNB at $412 \mathrm{~nm}$ using the plate reader. The blank comprised reaction mixture without TrxR. The compound blank (HS derivatives in assay buffer) was also processed in a similar manner to get the differential absorption of TNB at $412 \mathrm{~nm}$. The positive control comprised reaction mixture without $\mathrm{HS}$ or its derivatives. The activity is expressed as the percentage (\%) of the control. The final concentration of DMSO was $4 \%(\mathrm{v} / \mathrm{v})$, and the control had the same amount of DMSO.

4.6. Cell Cycle Analysis by PI Staining. PI staining was done at $48 \mathrm{~h}$ after treatment with $\mathrm{HS}$ and its derivatives. In brief, cells $\left(1 \times 10^{6}\right)$ were stained with a solution containing 50 $\mu \mathrm{g} \mathrm{mL}^{-1} \mathrm{PI}, 0.1 \%$ sodium citrate, and $0.1 \%$ Triton $\mathrm{X}-100$ and kept overnight at $4{ }^{\circ} \mathrm{C}$ in the dark. The labeled cells were acquired using a flow cytometer (Partec, Germany) and characterized for cell cycle phases using FlowJo software. The pre-G1 phase population represented the apoptotic cells. ${ }^{46}$

4.7. Molecular Docking Studies. The structures of HS, HP, HME, and HMEP were docked on the crystal structure of cytosolic TrxR (PDB file number 1H6V) using LeadIT 2.1.3FlexX (BioSolveIT, GmbH, Germany) docking software. As HS and HME are involved in keto-enol tautomerism, both the forms were independently used for docking studies. In the case of HP and HMPE, desmotropic forms were used for docking studies. All the isomeric and tautomeric forms were drawn in Gaussview programme, and the structures were cleaned for correct bond angle and bond length before subjecting to docking analysis. Of the six chains present in the structure of TrxR (1H6V), the dimer formed by chains $\mathrm{E}$ and $\mathrm{F}$ was considered for docking studies primarily because of the higher number of solved residues and the presence of catalytically active domains. To identify the binding site, amino acid residues such a $1-163$ and 297-367 from FAD-binding domain, 164-296 from NADPH-binding domain, and 368499 from interface domain (where the disulfides are reduced) were docked with the ligands. The interaction between ligand and amino acid residues was analyzed by combining both enthalpy- and entropy-based approaches as mentioned in a previous report. ${ }^{50}$ The favored pose of the ligand on the protein was evaluated by the scoring method followed by calculation of binding free energy using the in-built HYDE program of the docking software.
4.8. Real-Time Polymerase Chain Reaction (RT-PCR. The expression of $\gamma$-GCL was monitored by performing RTPCR. In brief, total RNA was isolated from cells at $48 \mathrm{~h}$ after treatment with $\mathrm{HS}$ or its derivatives using the TRI reagent. Approximately, $2 \mu \mathrm{g}$ of the total RNA was used for cDNA synthesis by reverse transcription (cDNA synthesis kit, Thermo Scientific, USA), and real-time PCR was carried out using the template (cDNA), SYBR green master mix (Roche Applied Science, Germany), and gene-specific primers in a Rotor-Gene Q (QIAGEN, Germany), according to the protocol standardized earlier. ${ }^{51}$ The threshold cycle (CT) values estimated from the above runs for the target genes were normalized against a housekeeping gene, b-actin, according to the method described earlier. ${ }^{52}$ The primers (forward and reverse) used for cDNA amplification are $\gamma \mathrm{GCL}$ (forward): 5'-GGGGTGACGAGGTGGAGTA-3' , $\gamma$ GCL (reverse): $5^{\prime}$ GTTGGGGTTTGTCCTCTCCC-3', $\beta$ Actin (forward): $5^{\prime}$ GGCTGTATTCCCCTCCATCG-3', and $\beta$ Actin (reverse): $5^{\prime}$ CCAGTTGGTAACAATGCCATGT-3'.

4.9. Antigenotoxic Studies. For antigenotoxic studies, $\mathrm{CHO}$ cells were incubated with $\mathrm{HS}$ or its derivatives for $2 \mathrm{~h}$, washed with PBS ( $\mathrm{pH} 7.4)$, supplemented with serum-free medium, and irradiated using ${ }^{60} \mathrm{Co}$ Blood Irradiator 2000 (BRIT, India) at a dose rate of $1 \mathrm{~Gy} / \mathrm{min}$. Following this, $10 \%$ FBS was added to the culture medium, and cells were incubated in a humidified atmosphere with $5 \% \mathrm{CO}_{2}$ at $37{ }^{\circ} \mathrm{C}$ and processed for micronuclei and $\gamma-\mathrm{H} 2 \mathrm{AX}$ and comet assays at desired time points.

4.10. Micronuclei Assay. Micronuclei assay was performed to determine the extent of residual DNA damage following irradiation. For this, cells were incubated with cytochalasin B (4 $\mu \mathrm{g} / \mathrm{mL}$ ) for $18 \mathrm{~h}$ to block cytokinesis and processed for micronuclei detection using acridine orange as reported previously. ${ }^{53}$ A total of 500 binucleated cells were analyzed for the presence of micronuclei per treatment condition. The NDI was calculated using the following formula:

$$
\mathrm{NDI}=\frac{[\mathrm{M} 1+2(\mathrm{M} 2)+3(\mathrm{M} 3)+4(\mathrm{M} 4)]}{N}
$$

where M1, M2, M3, and M4 are the number of cells with 1, 2, 3 , and 4 nuclei, respectively, and $N$ is the total number of viable cells. For NDI estimation, at least 500 viable cells were analyzed.

4.11. $\gamma-\mathrm{H} 2 \mathrm{AX}$ Assay. The $\gamma-\mathrm{H} 2 \mathrm{AX}$ assay was performed to assess the extent of acute DNA damage at $30 \mathrm{~min}$ postirradiation by the immunofluorescence method described in our previous report. ${ }^{53}$ The numbers of $\gamma \mathrm{H} 2 \mathrm{AX}$ foci in the nucleus of at least 50 cells under each treatment condition was counted using automated slide scanning and foci scoring Metacyte software module of the Metafer 4 scanning system (MetaSystems, Altlussheim, Germany).

4.12. Single-Cell Alkaline Gel Electrophoresis. Singlecell alkaline gel electrophoresis or comet assay was performed as a function of time $(0,30$, and $60 \mathrm{~min})$ to assess the DNA repair kinetics postirradiation. In brief, $\sim 15000$ cells (mixed with $0.8 \%$ low melting point agarose) layered on a slide were lysed, subjected to electrophoresis under alkaline conditions, and stained with SYBR Green-II. The methods of slide preparation, lysis, and the electrophoresis are mentioned in previous reports. ${ }^{54}$ The slides were imaged using a Carl Zeiss Axioplan fluorescent microscope (Germany), and about, 50 cells per slide were grabbed. The images were analyzed using 
CASP software version 1.2.0 (www.Casplab.com) to calculate DNA damage parameters such as TL and OTM.

4.13. Measurement of ROS. The intracellular levels of ROS were monitored at $30 \mathrm{~min}$ postirradiation. For this, cells $\left(1 \times 10^{4}\right)$ were labeled with a cell permeable and oxidation sensitive fluorescence probe, DCFDA $(5 \mu \mathrm{M})$, for $30 \mathrm{~min}$ at 37 ${ }^{\circ} \mathrm{C}$. ${ }^{55}$ The ROS level is represented as the fluorescence intensity of DCF detected by monitoring the emission at $530 \mathrm{~nm}$ after excitation at $488 \mathrm{~nm}$ on a multimode plate reader (Synergy H1, Biotek, Germany).

4.14. Statistical Analysis. All the experiments were carried out in triplicate and repeated at least two times. The results are presented as mean \pm (SEM), $n=3$ from an independent experiment. The data were analyzed by one-way ANOVA using Origin (version 6.1) software to confirm the variability of the data. The $p$ values $<0.05$ were considered as statistically significant.

\section{ASSOCIATED CONTENT}

\section{S Supporting Information}

The Supporting Information is available free of charge on the ACS Publications website at DOI: 10.1021/acsomega.8b00415.

Free energy $(\Delta G)$ change for the interaction of different conformers of HS derivatives with the NADPH domain of TrxR, cell cycle analysis in A549 cells, inhibition of TrxR by HS derivatives in cell-free systems, LineweaverBurk plot showing the effect of varying $\mathrm{NADPH}$ concentration on the activity of TrxR in the presence of HS derivatives, chemical structures of the different conformers of HS derivatives, and fluorescence images of $\mathrm{CHO}$ cells indicating micronuclei (PDF)

\section{AUTHOR INFORMATION}

\section{Corresponding Authors}

*E-mail: kamit@barc.gov.in. Phone: 91-22-25592352. Fax: 9122-25505151 (A.K.).

*E-mail: atanu@barc.gov.in (A.B.).

ORCID

Amit Kunwar: 0000-0003-1017-1527

Author Contributions

${ }^{\perp}$ P.C., S.S.I., and V.V.G. contributions to the research work.

Notes

The authors declare no competing financial interest.

\section{ACKNOWLEDGMENTS}

The author (V.G.) acknowledges Homi Bhabha National Institute for financial assistance in the form of Junior Research Fellowship. The authors are also grateful to V. P. Saka, Indian Academy Summer Research Fellow, B. S. Patro of Bio-organic Division, and R. K. Chaurasia, Radiological Physics and Advisory Division for their assistance during the course of experiments.

\section{REFERENCES}

(1) Cragg, G. M.; Newman, D. J. Natural products: a continuing source of novel drug leads. Biochim. Biophys. Acta 2013, 1830, 36703695.

(2) Schumacher, M.; Juncker, T.; Schnekenburger, M.; Gaascht, F.; Diederich, M. Natural compounds as inflammation inhibitors. Genes Nutr. 2011, 6, 89-92.

(3) Veeresham, C. Natural products derived from plants as a source of drugs. J. Adv. Pharm. Technol. Res. 2012, 3, 200-201.
(4) Bernardini, S.; Tiezzi, A.; Laghezza Masci, V.; Ovidi, E. Natural products for human health: an historical overview of the drug discovery approaches. Nat. Prod. Res. 2017, 27, 1-25.

(5) Dias, D. A.; Urban, S.; Roessner, U. A historical overview of natural products in drug discovery. Metabolites 2012, 2, 303-336.

(6) Gu, J.; Gui, Y.; Chen, L.; Yuan, G.; Lu, H.-Z.; Xu, X. Use of natural products as chemical library for drug discovery and network pharmacology. PLoS One 2013, 8, No. e62839.

(7) Pascolutti, M.; Quinn, R. J. Natural products as lead structures: chemical transformations to create lead-like libraries. Drug Discovery Today 2014, 19, 215-221.

(8) Ali, N. A. A.; Jansen, R.; Pilgrim, H.; Liberra, K.; Lindequist, U. Hispolon, a yellow pigment from inonotus hispidus. Phytochemistry 1996, 41, 927-929.

(9) Mo, S.; Wang, S.; Zhou, G.; Yang, Y.; Li, Y.; Chen, X.; Shi, J. Phelligridins C-F: cytotoxic pyrano[4,3-c][2] benzopyran-1,6-dione and furo[3,2-c]pyran-4-one derivatives from the fungus Phellinus igniarius. J. Nat. Prod. 2004, 67, 823-828.

(10) Wang, J.; Hu, F.; Luo, Y.; Luo, H.; Huang, N.; Cheng, F.; Deng, Z.; Deng, W.; Zou, K. Estrogenic and anti-estrogenic activities of hispolon from Phellinus lonicerinus (Bond.). Fitoterapia 2014, 95, 93101.

(11) Ali, N. A. A.; Mothana, R. A. A.; Lesnau, A.; Pilgrim, H.; Lindequist, U. Antiviral activity of Inonotus hispidus. Fitoterapia 2003, $74,483-485$.

(12) Huang, G.-J.; Deng, J.-S.; Chiu, C.-S.; Liao, J.-C.; Hsieh, W.-T.; Sheu, M.-J.; $\mathrm{Wu}, \mathrm{C}$.-H. Hispolon protects against acute liver damage in the rat by inhibiting lipid peroxidation, proinflammatory cytokine, oxidative stress and down-regulating the expressions of iNOS, COX-2, and MMP-9. J. Evidence-Based Complementary Altern. Med. 2012, 2012, 480714.

(13) Chang, H.-Y.; Sheu, M.-J.; Yang, C.-H.; Lu, T.-C.; Chang, Y.-S.; Peng, W.-H.; Huang, S.-S.; Huang, G.-J. Analgesic effects and the mechanisms of anti-inflammation of hispolon in mice. J. Evidence-Based Complementary Altern. Med. 2011, 2011, 478246.

(14) Huang, G.-J.; Deng, J.-S.; Huang, S.-S.; Hu, M.-L. Hispolon induces apoptosis and cell cycle arrest of human hepatocellular carcinoma Hep3B cells by modulating ERK phosphorylation. J. Agric. Food Chem. 2011, 59, 7104-7113.

(15) Chen, Y.-C.; Chang, H.-Y.; Deng, J.-S.; Chen, J.-J.; Huang, S.-S.; Lin, I.-H.; Kuo, W.-L.; Chao, W.; Huang, G.-J. Hispolon from Phellinus linteus induces G0/G1 cell cycle arrest and apoptosis in NB4 human leukaemia cells. Am. J. Chin. Med. 2013, 41, 1439-1457.

(16) Wu, Q.; Kang, Y.; Zhang, H.; Wang, H.; Liu, Y.; Wang, J. The anticancer effects of hispolon on lung cancer cells. Biochem. Biophys. Res. Commun. 2014, 453, 385-391.

(17) Chen, W.; Zhao, Z.; Li, L.; Wu, B.; Chen, S.-F.; Zhou, H.; Wang, Y.; Li, Y.-Q. Hispolon induces apoptosis in human gastric cancer cells through a ROS-mediated mitochondrial pathway. Free Radical Biol. Med. 2008, 45, 60-72.

(18) Huang, G.-J.; Yang, C.-M.; Chang, Y.-S.; Amagaya, S.; Wang, H.C.; Hou, W.-C.; Huang, S.-S.; Hu, M.-L. Hispolon suppresses SKHep1 human hepatoma cell metastasis by inhibiting matrix metalloproteinase-2/9 and urokinase-plasminogen activator through the PI3K/Akt and ERK signaling pathways. J. Agric. Food Chem. 2010, 58, 9468-9475.

(19) Hsiao, P.-C.; Hsieh, Y.-H.; Chow, J.-M.; Yang, S.-F.; Hsiao, M.; Hua, K.-T.; Lin, C.-H.; Chen, H.-Y.; Chien, M.-H. Hispolon induces apoptosis through JNK1/2-mediated activation of a Caspase-8, -9, and -3-dependent pathway in Acute Myeloid Leukemia (AML) cells and inhibits AML Xenograft tumor growth in vivo. J. Agric. Food Chem. 2013, 61, 10063-10073.

(20) Balaji, N. V.; Babu, B. H.; Subbaraju, G. V.; Nagasree, K. P.; Kumar, M. M. K. Synthesis, screening and docking analysis of hispolon analogs as potential antitubercular agents. Bioorg. Med. Chem. Lett. 2017, 27, 11-15.

(21) Balaji, N. V.; Ramani, M. V.; Viana, A. G.; Sanglard, L. P.; White, J.; Mulabagal, V.; Lee, C.; Gana, T. J.; Egiebor, N. O.; Subbaraju, G. V.; Tiwari, A. K. Design, synthesis and in vitro cell-based evaluation of the 
anti-cancer activities of hispolon analogs. Bioorg. Med. Chem. 2015, 23, $2148-2158$

(22) Shaikh, S. A. M.; Barik, A.; Singh, B. G.; Madukuri, R. V.; Balaji, N. V.; Subbaraju, G. V.; Naik, D. B.; Priyadrsini, K. I. Free radical reactions of isoxazole and pyrazole derivatives of hispolon: kinetics correlated with molecular descriptors. Free Radical Res. 2016, 50, 1361-1373.

(23) Little, J. B. Radiation carcinogenesis. Carcinogenesis 2000, 21, 397-404.

(24) Poirier, M. C. Chemical-induced DNA damage and human cancer risk. Discov. Med. 2012, 14, 283-288.

(25) Kryston, T. B.; Georgiev, A. B.; Pissis, P.; Georgakilas, A. G. Role of oxidative stress and DNA damage in human carcinogenesis. Mutat. Res. 2011, 711, 193-201.

(26) Khan, N.; Afaq, F.; Mukhtar, H. Cancer chemoprevention through dietary antioxidants: progress and promise. Antioxid. Redox Signaling 2008, 10, 475-510.

(27) Halliwell, B. The antioxidant paradox: less paradoxical now? Br. J. Clin. Pharmacol. 2013, 75, 637-644.

(28) León-González, A. J.; Auger, C.; Schini-Kerth, V. B. Pro-oxidant activity of polyphenols and its implication on cancer chemoprevention and chemotherapy. Biochem. Pharmacol. 2015, 98, 371-380.

(29) Espinosa-Diez, C.; Miguel, V.; Mennerich, D.; Kietzmann, T.; Sánchez-Pérez, P.; Cadenas, S.; Lamas, S. Antioxidant responses and cellular adjustments to oxidative stress. Redox Biol. 2015, 6, 183-197.

(30) Trotter, E. W.; Grant, C. M. Thioredoxins are required for protection against a reductive stress in the yeast Saccharomyces cerevisiae. Mol. Microbiol. 2002, 46, 869-878.

(31) Chaurasia, R. K.; Balakrishnan, S.; Kunwar, A.; Yadav, U.; Bhat, N.; Anjaria, K.; Nairy, R.; Sapra, B. K.; Jain, V. K.; Priyadarsini, K. I. Cyto-genotoxicity assessment of potential radioprotector, 3,3'diselenodipropionic acid (DSePA) in Chinese Hamster Ovary (CHO) cells and human peripheral blood lymphocytes. Mutat. Res., Genet. Toxicol. Environ. Mutagen. 2014, 774, 8-16.

(32) Kirsch-Volders, M.; Decordier, I.; Elhajouji, A.; Plas, G.; Aardema, M. J.; Fenech, M. In vitro genotoxicity testing using the micronucleus assay in cell lines, human lymphocytes and 3D human skin models. Mutagenesis 2011, 26, 177-184.

(33) Wang, Y.-J.; Pan, M.-H.; Cheng, A.-L.; Lin, L.-I.; Ho, Y.-S.; Hsieh, C.-Y.; Lin, J.-K. Stability of curcumin in buffer solutions and characterization of its degradation products. J. Pharm. Biomed. Anal. 1997, 15, 1867-1876.

(34) Schneider, C.; Gordon, O. N.; Edwards, R. L.; Luis, P. B. Degradation of curcumin: From mechanism to biological implications. J. Agric. Food Chem. 2015, 63, 7606-7614.

(35) Lee, W.-H.; Loo, C.-Y.; Bebawy, M.; Luk, F.; Mason, R.; Rohanizadeh, R. Curcumin and its derivatives: their application in neuropharmacology and neuroscience in the 21st century. Curr. Neuropharmacol. 2013, 11, 338-378.

(36) Schafer, F. Q.; Buettner, G. R. Redox environment of the cell as viewed through the redox state of the glutathione disulfide/glutathione couple. Free Radical Biol. Med. 2001, 30, 1191-1212.

(37) Zhang, H.; Limphong, P.; Pieper, J.; Liu, Q.; Rodesch, C. K.; Christians, E.; Benjamin, I. J. Glutathione-dependent reductive stress triggers mitochondrial oxidation and cytotoxicity. FASEB J. 2012, 26, 1442-1451.

(38) Fisher, D.; Mentor, S. Antioxidant-induced reductive stress has untoward consequences on the brain microvasculature. Neural Regener. Res. 2017, 12, 743-744.

(39) Koc, A.; Mathews, C. K.; Wheeler, L. J.; Gross, M. K.; Merrill, G. F. Thioredoxin is required for deoxyribonucleotide pool maintenance during S phase. J. Biol. Chem. 2006, 281, 15058-15063.

(40) Lu, J.; Papp, L. V.; Fang, J.; Rodriguez-Nieto, S.; Zhivotovsky, B.; Holmgren, A. Inhibition of mammalian thioredoxin reductase by some flavonoids: implications for myricetin and quercetin anticancer activity. Cancer Res. 2006, 66, 4410-4418.

(41) Saccoccia, F.; Angelucci, F.; Boumis, G.; Carotti, D.; Desiato, G.; Miele, A.; Bellelli, A. Thioredoxin reductase and its inhibitors. Curr. Protein Pept. Sci. 2014, 15, 621-646.
(42) Singh, D. V.; Agarwal, S.; Kesharwani, R. K.; Misra, K. 3D QSAR and pharmacophore study of curcuminoids and curcumin analogs: interaction with thioredoxin reductase. Interdiscip. Sci.: Comput. Life Sci. 2013, 5, 286-295.

(43) Lincoln, D. T.; Ali Emadi, E. M.; Tonissen, K. F.; Clarke, F. M. The thioredoxin-thioredoxin reductase system: over-expression in human cancer. Anticancer Res. 2003, 23, 2425-2433.

(44) Hall, E. J.; Giaccia, A. J. Radiobiology for the Radiologist; Wolters Kluwer Press, 2006; pp 1-546.

(45) Riley, P. A. Free radicals in biology: oxidative stress and the effects of ionizing radiation. Int. J. Radiat. Biol. 1994, 65, 27-33.

(46) Kunwar, A.; Narang, H.; Priyadarsini, K. I.; Krishna, M.; Pandey, R.; Sainis, K. B. Delayed activation of PKC $\delta$ and $\mathrm{NF} \kappa \mathrm{B}$ and higher radioprotection in splenic lymphocytes by copper(II)-curcumin (1:1) complex as compared to curcumin. J. Cell. Biochem. 2007, 102, 12141224.

(47) Mosmann, T. Rapid colorimetric assay for cellular growth and survival: application to proliferation and cytotoxicity assays. J. Immunol. Methods 1983, 65, 55-63.

(48) Hissin, P. J.; Hilf, R. A fluorometric method for determination of oxidized and reduced glutathione in tissues. Anal. Biochem. 1976, 74, 214-226.

(49) Fang, J.; Lu, J.; Holmgren, A. Thioredoxin reductase is irreversibly modified by curcumin: a novel molecular mechanism for its anticancer activity. J. Biol. Chem. 2005, 280, 25284-25290.

(50) Forino, M.; Jung, D.; Easton, J. B.; Houghton, P. J.; Pellecchia, M. Virtual docking approaches to protein kinase B inhibition. J. Med. Chem. 2005, 48, 2278-2281.

(51) Verma, P.; Kunwar, A.; Arai, K.; Iwaoka, M.; Priyadarsini, K. I. Alkyl chain modulated cytotoxicity and antioxidant activity of bioinspired amphiphilic selenolanes. Toxicol. Res. 2016, 5, 434-445.

(52) Livak, K. J.; Schmittgen, T. D. Analysis of relative gene expression data using real-time quantitative PCR and the 2(-Delta Delta C(T)) method. Methods 2001, 25, 402-408.

(53) Chaurasia, R. K.; Balakrishnan, S.; Kunwar, A.; Yadav, U.; Bhat, N.; Anjaria, K.; Nairy, R.; Sapra, B. K.; Jain, V. K.; Priyadarsini, K. I. Cyto-genotoxicity assessment of potential radioprotector, 3,3'diselenodipropionic acid (DSePA) in Chinese Hamster Ovary (CHO) cells and human peripheral blood lymphocytes. Mutat. Res., Genet. Toxicol. Environ. Mutagen. 2014, 774, 8-16.

(54) Sandhya, T.; Lathika, K. M.; Pandey, B. N.; Bhilwade, H. N.; Chaubey, R. C.; Priyadarsini, K. I.; Mishra, K. P. Protection against radiation oxidative damage in mice by triphala. Mutat. Res. 2006, 609, $17-25$.

(55) Kunwar, A.; Jayakumar, S.; Srivastava, A. K.; Priyadarsini, K. I. Dimethoxycurcumin- induced cell death in human breast carcinoma MCF7 cells: evidence for pro-oxidant activity, mitochondrial dysfunction, and apoptosis. Arch. Toxicol. 2012, 86, 603-614. 